\title{
Factors affecting the pregnancy rate in transfers of embryos in crossbreed Brown Swiss
}

\begin{abstract}
In vivo embryo transfer was carried out in crossbred Brown Swiss cows from the influential provinces of National Toribio Rodriguez de Mendoza University (UNTRM) experimental stations, from the beginning of the autumn season of 2013 to the end of spring season of 2015, for which states of transfers. Transfers were used mainly in receptors crossbred Brown Swiss cows, with a population of 126 receptors cows aged 2 to 9 years with a number of births ranging from 0 to 7 , of which 74 transfers were performed with embryos fresh and 52 with frozen embryos. After 28 to 35 days of transfer of the embryo, gestation was evaluated by ultrasonography. With the objective of obtaining a pregnancy rate by state and the totality of the transfers, they were evaluated with the ANDEVA technique with a statistical significance of $5 \%$. Obtaining that the pregnancy rate presented a significant statistical variation due to factors like the station and the state (fresh or frozen). Likewise, the value of total embryo transfer was $46.0 \%$, while embryo transfer in the fresh and frozen state was $54.1 \%$ and $34.6 \%$, respectively, and it was considered successful.
\end{abstract}

Volume 5 Issue 2 - 2018

\author{
Deyvis Julón, Nilton Burga, William Bardales, \\ Víctor Puicón \\ Universidad Nacional Toribio Rodríguez de Mendoza, Peru
}

Correspondence: Víctor Puicón, Universidad Nacional Toribio Rodríguez de Mendoza, Núcleo de Mejoramiento Genético IGBI, Peru, Email victor_puicon_1704@hotmail.com

Received: December 14, 2017 | Published: March 20, 2018

Keywords: embryos, transfer, donors, receptors, superovulation

\section{Introduction}

Embryo transfer is one of the techniques of reproductive biotechnology that helps us to take advantage of the genetic value in bovine production, allowing to raise the number of standards of quality and efficiency, since it increases especially unexcellent genetic potential, simultaneously shortening the generational interval. In addition, it facilitates different breeding activities such as progeny assessment and comparison between groups of animals.

Currently Peru along with other countries of tropical regions seek to have the need to increase $B$ indicus in the complex phenomenon of reproduction, thus improving reproductive and genetic efficiency, ${ }^{2}$ this is the highest degree that only represents the first step towards new biotechnologies in our region. While the high potential impact caused by climate changes in the livestock sector, have not been fully included or studied to determine the technical options in this sector. ${ }^{3}$ Climate change has direct effects on livestock production and indirect effects on changes in the availability, quantity and quality of different food sources. ${ }^{4}$

According to Kafi and McGowan classify the intrinsic and extrinsic factors. However, the climate patterns continue to change within a more intense cycle, causing factors that could affect the results of the pregnancy rates, which have different origins currently observed.

Economic viability is crucial to ensure the sustainability of livestock operations and the development of applications of new techniques, which can be altered by environmental factors such as hours of light, temperature and rainfall, giving rise to early warnings in breeding programs in some species. ${ }^{5}$ The population in general terms observes the problem of the national cattle ranching that is mainly linked to a low production and productivity that represents a low profitability of this activity. The main causes of these problems are the seasonality of production, changes in the availability of quantity and quality of pastures and forages, low reproductive rates, high mortality rates in replacement breeding, high production costs of intensive livestock, shortages and high price of bellies, low milk and meat quality, and technological delay.

One of the main factors that determine economic success in a livestock operation for various purposes is reproductive efficiency; Ideally, one breeding per year of each breeding cow should be obtained, however, obtaining replacement females with high genetic quality in dairy farming is not easy, because almost all females are kept as possible future replacements. The specialized dairy producers would like to control the sex ratio of the offspring born in their farms, looking predominantly for females and, thus, increasing the population size from which to select. ${ }^{6,7}$

In both natural and artificial insemination (AI), the proportion of sex in the offspring is $50 \%$ males and $50 \%$ females. ${ }^{8}{ }^{89}$ However, when using superovulation and embryo transfer (TE), there is a higher proportion of males attributed to factors related to the degree of development and quality of the transferred embryos, ${ }^{7,9,10}$ as well as the male reproductive used in AI. ${ }^{11}$ It should be noted that According to Ealy et al. ${ }^{12}$ high temperatures during the summer delay embryonic development because embryos have a lower capacity to secrete interferon, which is the signal for maternal recognition of pregnancy. The objective of the present study was to determine the proportion of sex ness originating from embryo transfer and to identify factors that could modify this proportion.

\section{Materials and methods}

The study began in February 1996 and was completed in August 1997. We used 73 crossbred Brown Swiss cows from two to nine years of age (of one birth or more), of which 39 were of high body condition (CCA), between 5.5 and $7(X=6.4 \pm 0.5)$ and 34 of low body condition (BCC), from 3 to $4.5(X=4.1 \pm 0.4)$, on a scale of 1 (emaciated) and of 9 (extremely obese).

The body condition (CC) of the cows was evaluated and recorded in four moments: at parturition, when presenting the first corpus luteum (CL) postpartum, at estrus and at the beginning of the breeding. 


\section{Characteristics of the field of study}

The present investigation was carried out in the bovine cattle of the provinces of Bongará, Chachapoyas, Luya and Rodríguez de Mendoza in the Amazonas region, zones of influence of the Experimental Stations of the National University Toribio Rodríguez de Mendoza, in which results are reported from the beginning from the autumn season of 2013 until the end of spring of 2015, managed by personnel specialized in embryo transfer using the latest generation technology (Figure 1).

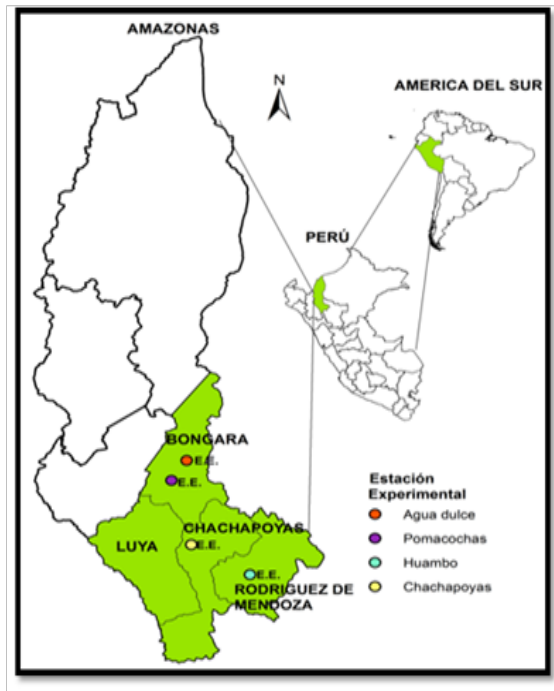

Figure I Map of the zones of influence of the experimental stations of the National University Toribio Rodríguez de Mendoza - Amazonas.

\section{Evaluation and selection of recipients}

In the present study, 86 recipients of the Brown Swiss breed, aged 3 to 7 years, from 0 to 7 calving numbers, with a body condition of 2.5 to 3.5 were selected. Two transfer states were evaluated. Embryos in cows of the crossed Brown Swiss race, reporting pregnancy rates.

The body condition was categorized as 3.25 or greater than 3.25 , in order to analyze its relationship with the diameter of the major follicle, the degree of body condition of the cows at birth represents the most important factor affecting the interval of labor to estrus and the pregnancy rate in multiparous cows. Likewise, biostimulated cows (exposed to bulls) initiate estrus cycles earlier than non-biostimulated cows, thus the effect of biostimulation with bulls in the postpartum is more marked in cows with lower body condition than in cows with greater body condition.

\section{Implementation of the heat synchronization protocol}

In the protocol, the following days were worked on: day (0) placing progesterone (P4) estradiol benzoate $(\mathrm{BE})$, prostaglandin (PG) and equine gonadotropin (eCG) as follows: P4 $0.8 \mathrm{~mL} \mathrm{BE} 2.5$ $\mathrm{mL}$ PG foaming ovule, day (5) eCG 2Ml, day (8) withdrawal of P4 2.5 PG, day (9) $0.4 \mathrm{~mL} \mathrm{BE}$, day (10) visual observation of heat, day (16) evaluation by rectal palpation of ovaries and uterus of recipients ( presence of functional corpus luteum in ovaries and flaccid uterus) and day (17) embryo transfer.

\section{Embryo collection and its classification}

The hygiene of the working areas of the cow, the ovarian evaluation (right, left), application of the anesthesia, installation of the collection means, dilation of the cervix, fixation of the Foley catheter, embryo collection, filter washing, search and classification of embryos.

\section{Embryo transfer}

The embryo transfer was performed with the evaluation of the ovarian response (corpus luteum $>16 \mathrm{~mm}$ ).

\section{Pregnancy diagnosis}

The pregnancy evaluation was carried out 28 to 35 days after the embryo was transferred, by means of ultrasonography (Portable Ultrasound).

\section{Results and discussion}

According to the results obtained, it can be deduced that the pregnancy rate corresponding to the embryo transfer of each station and by state presented a significant difference $(\mathrm{p}>0.05)$ (Table 1$)$.

Table I Pregnancy rate according to seasons

\begin{tabular}{lll}
\hline \multirow{2}{*}{ Seasons } & \multicolumn{2}{l}{$\%$ of pregnancy } \\
\cline { 2 - 3 } & State & \\
\cline { 2 - 3 } & Frozen & Cool \\
\hline Spring & 100,0 & 50,0 \\
Summer & 42,1 & 0,0 \\
Autumn & 25,0 & 59,1 \\
Winter & 0,0 & 63,2
\end{tabular}

$\%$ of Pregnancy, percentage of pregnancy

Table 2 shows that there are a greater number of transfers in the summer season with a total of 19 transfers, 8 in autumn and 1 in winter and spring respectively. Also the best pregnancy rate was observed in the spring season with $100 \%(1 / 1)$, followed by summer $42.1 \%(8 / 19)$, autumn $25.0 \%(2 / 8)$ and finally, winter with $0.0 \%(0 / 1)$ respectively.

Table 2 Pregnancy rate of the frozen state for each season

\begin{tabular}{llllll}
\hline \multirow{2}{*}{ Seasons } & \multirow{2}{*}{ No. transfer } & \multicolumn{2}{c}{ Reproductive state } & \% of \\
\cline { 3 - 4 } & & Pregnant & Empty & pregnancy \\
\hline Spring & I & I & 0 & 100,0 \\
Summer & 19 & 8 & II & 42,1 \\
Autumn & 8 & 2 & 6 & 25,0 \\
Winter & I & 0 & I & 0,0 \\
\hline
\end{tabular}

$\%$ of Pregnancy, percentage of pregnancy

Table 3 shows that the largest number of transfers was made in the fall season with a total of 22 transfers, 19 in winter, 16 in spring and 0 in summer respectively. Also the best pregnancy rate was obtained in the winter season $63.2 \%(12 / 19)$, autumn with $59.1 \%(13 / 22)$, spring with $50.0 \%(8 / 16)$ and last season summer $0.0 \%(0 / 0)$ respectively.

Table 3 Pregnancy index of the fresh state for each season

\begin{tabular}{lllll}
\hline Seasons & No.transfer & $\begin{array}{l}\text { Reproductive } \\
\text { state }\end{array}$ & Pregnant & $\begin{array}{l}\text { \% of } \\
\text { pregnancy }\end{array}$ \\
\cline { 3 - 4 } & & 8 & 8 & 50,0 \\
\hline Spring & 16 & 0 & 0 & 0,0 \\
Summer & 0 & 13 & 9 & 59,1 \\
Autumn & 22 & 12 & 7 & 63,2 \\
Winter & 19 & & & \\
\hline
\end{tabular}

$\%$ of Pregnancy, percentage of pregnancy 
In Table 4, it can be inferred that of the total transfers made in this study, the best season of the year to carry out this technique was the winter season because it represented $60.0 \%$ pregnancy rate, spring as the second season, autumn and summer as the last two seasons.

Table 4 Pregnancy rate of total transfers per station

\begin{tabular}{lllll} 
Seasons & No. transfer & $\begin{array}{l}\text { Reproductive } \\
\text { state }\end{array}$ & $\begin{array}{l}\text { \% of } \\
\text { pregnancy }\end{array}$ \\
\cline { 3 - 4 } & & Pregnant & Empty & \\
\hline Spring & 17 & 9 & 8 & 53,0 \\
Summer & 19 & 8 & 11 & 42,1 \\
Autumn & 30 & 15 & 15 & 50,0 \\
Winter & 20 & 12 & 8 & 60,0 \\
\hline
\end{tabular}

$\%$ of Pregnancy, percentage of pregnancy

Hasler ${ }^{13}$ conducted a study on the factors that affect pregnancy by embryo transfer in a conventional manner, indicating that he did not find differences $(\mathrm{p}>0.05)$ in pregnancy rates for the different seasons, spring $68.8 \%$, summer $67.7 \%$, autumn $67.8 \%$ and winter $68.5 \%$, while, in Table 4, statistical differences were found in the percentages of pregnancy in the different seasons, spring $53.0 \%$, summer $42.1 \%$, autumn $50.0 \%$ and winter $60.0 \%$.

When evaluating the success of the transfer, individually from the variables contributed by the embryo, we can see in Table 1 , that the highest pregnancy rate, presents the state of fresh embryo transfer, which could determine, not only the capacity to gestate the transferred embryo, but also to be able to raise it more efficiently. However, in other studies, significant differences were found in pregnancy rates between states,,$^{14}$ while in other studies they did not find significant differences when using heifers or cows ${ }^{15}$ that our obtained result could be valid for multiparous cows.

In Table 2, it can be said that embryos in fresh and frozen represent $54.1 \%$ and $34.6 \%$ pregnancy rate respectively, but according to Spell et al. ${ }^{16}$ report that they have worked with Angus females, of which pregnancy rates with fresh and frozen embryos were $83 \%$ and $69 \%$ respectively, higher than the rates reported in the present study. This could be due to the fact that in our study we have worked with the Brown Swiss breed, which is a dual purpose breed while the Angus breed is for a single purpose.

In Colombia, results have been reported using female recipients of embryos of different racial types and crosses, so Rodríguez et al. ${ }^{17}$ in a study conducted in the middle and lower Colombian tropics report pregnancy rates with fresh embryos of $31 \%$ and, frozen at $46 \%$. The results according to this author and related to our results, are only higher in the pregnancy rate $54.1 \%$ in fresh state and frozen state is lower with $34.6 \%$, which could be due to the conditions of in vitro embryos transferred in some proportion or in the referential study, among others, and to a lesser degree to the worked racial typologies, since according to what was previously mentioned, different pregnancy rates have been obtained using racial typologies. ${ }^{18-20}$

In cattle Bos Indicus, without embryo transfer programs or hormonal treatments, Aguirre et al. ${ }^{21}$ reported $45 \%$ of pregnancy rate, however in Table 3 it is detailed that the pregnancy rate of this investigation was $46.0 \%$, stating that there was no significant difference, however, Cutini et al. ${ }^{22}$ reported that the success rate is, when the pregnancy technique after embryo transfer, is close to $60 \%$, including embryo transfer in the frozen state; In addition, Lohouis et al..$^{23}$ described that the pregnancy rate is successful when the averages vary from 40 to $70 \%$, even depending on the use of embryos whether fresh or frozen; of which our result was $46.0 \%$ which is located within the range according to the author, and concluding that our result was a pregnancy success rate.

Due to the similar percentage found in several other studies, such as Fuentes and De la Fuente, which used Holstein heifers, which were treated hormonally (1000 IU ECG on day 5 with reference to the start of treatment), reported indices of pregnancy with embryos frozen in glycerol of $54 \%$, in ethylene glycol of $48 \%$ and fresh $52 \%$ (without statistical differences). However, in our study cows of crossed Brown Swiss breed were used, reporting pregnancy rates with frozen embryos of $34.6 \%$ and fresh $54.1 \%$ with a high percentage of difference, which could be dependent on the season of the year in which the study. ${ }^{24-27}$

\section{Conclusion}

A. The total pregnancy rate of embryo transfers was $46.0 \%$.

B. The pregnancy rates of embryo transfer in fresh and frozen state were $54.1 \%$ and $34.6 \%$ respectively.

C. In the winter season $(60.0 \%)$ the best pregnancy rates were obtained, followed by the spring, autumn and summer seasons respectively.

\section{Acknowledgements}

None.

\section{Conflict of interest}

The authors declare no conflict of interest.

\section{References}

1. Hafez ESE, Hafez B. Reproducción e inseminación artificial en animales. Mexico: McGraw-Hill Interamericana; 2002. 519 p.

2. Baruselli PS, de Sá Filho MF, Martins CM, et al. Superovulation and embryo transfer in Bos indicus cattle. Theriogenology. 2006;65(1):77-88.

3. Frank KL, Mader TL, Harrington JA, et al. Climate change effects on livestock production in the Great Plains. In: Livestock Environment VI: Proceedings of the 6 International Symposium. Louisville, Kentucky, USA: ASAE Publication; 2001:351-358.

4. Ministry of Agriculture Fisheries and Food (MAFF). Climate change and agriculture in the United Kingdom. London: MAFF; 2000. 65p.

5. Lindsay DR. Environment and reproductive behaviour. Anim Reprod Sci. 1996;42(1-4):1-12.

6. Thibier M, Nibart M. The sexing of bovine embryos in the field. Theriogenology. 1995;43(1):71-80.

7. Shea BF. Determining the sex of bovine embryos using polymerase chain reaction results: a six-year retrospective study. Theriogenology. 1999;51(4):841-854.

8. Callesen H, Liboriussen T, Greve T. Practical aspects of multiple ovulation-embryo transfer in cattle. Anim Reprod Sci. 1996;42(14):215-226.

9. van Wagtendonk-de Leeuw AM, Aerts BJ, den Daas JH. Abnormal offspring following in vitro production of bovine preimplantation embryos: a field study. Theriogenology. 1998;49(5):883-894. 
10. Avery B, Bak A, Schmidt M. Different cleavage rates and sex determination in bovine embryos. Theriogenology. 1989;32(1):139-147.

11. Avery B, Quetglas D. Evolution of day 8 and 9 in vitro derived bovine blastocysts, fertilized with two different bulls. Theriogenology. 1996;45(1):213-213.

12. Ealy AD, Drost M, Hansen PJ. Developmental changes in embryonic resistance to adverse effect of maternal heat stress in cows. J Dairy Sci. 1993;76(10):2899-2905.

13. Hasler J. Factors affecting frozen and fresh embryo transfer pregnancy rates in cattle. Theriogenology. 2001;56(9):1401-1415.

14. Kruip TAM, den Daas JHG. In vitro produced and cloned embryos: Effects on pregnancy, parturition and offspring. Theriogenology. 1997;47(1):43-52.

15. Munar CJ, Valdéz AM. Transferencia de embriones bovinos criopreservados con Etilienglicol y con Glicerol. Factores que afectan los resultados. Jornadas de Biotecnología. Universidad Nacional de Lomas de Zamora. 1998.

16. Spell AR, Beal WE, Corah LR, et al. Evaluating recipients and embryo factors that affect pregnancy rates of embryo transfer in beef cattle. Theriogenology. 2001;56(2):287-297.

17. Rodríguez JM, Giraldo C, Castañeda S, et al. Análisis multifactorial de las tazas de preñez en programas de transferencia de embriones en Colombia. Rev MVZ Córdoba. 2007;12(2):978-984.

18. Nogueira MFG, Melo DS, Carvalho LM, et al. Do high progesterone concentrations in embryos recipients synchronized with PGF and eCG?. Theriogenology. 2004;61(7-8):1283-1290.
19. Vos PL, van der Schans A, de Wit AA, et al. Effect of neutralization of pregnant mare's serum gonadotrophin (PMSG) shortly before or at the preovulatory LH surge in PMSG-superovulated heifers on follicular function and development. J Reprod Fertil. 1994;100(2):387-393.

20. Dieleman SJ, Bevers MM, Vos PLAM, et al. PMSG/anti-PMSG in cattle: a simple and efficient superovulatory treatment. Theriogenology. 1993;39(1):25-41.

21. Aguirre A, Pardo C, Góngora A. Inicio del celo, tasa de gestación y relación del tiempo de inseminación con los niveles de progesterona en vacas Brahman. Rev MVZ Córdoba. 2006;11(1):766-772.

22. Cutini A, Teruel M, Cabodevila J. Criopreservación de embriones de especies de interés pecuario. Rev Arg Prod Anim. 1999;19:447-469.

23. Lohouis MM, Smith C, Dekkers JCM. Results from a dispersed hybrid nucleus programmed in dairy cattle. Anim Prod. 1993;57:369-378.

24. Hornbuckle T, Ott RS, Ohl MW, et al. Effect of bull exposure on the cyclic activity of beef cows. Theriogenology. 1995;43(2):411-418.

25. Morrison DG, Spitzer JC, Perkins JL. Influence of prepartum body conditions score change on reproduction in multiparous beef cows calving in moderate body condition. J Anim Sci. 1999;77(5):1048-1054.

26. Stumpf TT, Wolfe MW, Wolfe PL, et al. Weight changes prepartum and presence of bulls postpartum interact to affect duration of postpartum anestrus in cows. J Anim Sci. 1992;70(10):3133-3137.

27. Richards MW, Spitzer JC, Warner MB. Effects of varying levels of postpartum nutrition and body condition at calving on subsequent reproductive performance in beef cattle. J Anim Sci. 1996;62:300-306. 